\title{
The Influence of Curing Agent Content on the Property of Stainless Steel Flakes Epoxy Intermediate Nano-coating
}

\author{
Sha-sha Li, Miao Lou, Ben-ben Yang, Ying Xu, Yu-feng Lu, Chun-miao Shen \\ and Li-rong Deng
}

Northwest Institute of Nuclear Technology, Xi'an 710024, China

Keywords: Curing Agent Content; Stainless Steel Flakes Epoxy Intermediate Nano-coating; Heavy-duty Organic Coating; Property

\begin{abstract}
To provide reference and according for further coating optimization, shorting process cycle and raising project benefit, the influence of curing agent content on the viscosity, applied time, hardness, combining power, drying time and corrosion resistance of the stainless steel flakes epoxy intermediate nano-coating had been studied. The results indicated as the curing agent content adding, the viscosity decrease, applied time short, drying time short, combining power and hardness both increase firstly and then decrease. But the corrosion resistance of the coating not influenced by the curing agent content adding.
\end{abstract}

\section{Introduction}

The enhancing the corrosion resistance of steel vessel repositing poison material, the heavy-duty organic coating is applicated on the vessel surface for prolonging the vessel life length. The heavy-duty organic coating is as shown as table 1 . The stainless steel flakes epoxy intermediate nano-coating in the heavy-duty organic coating has a large number of different size parallel arrangement stainless steel flakes that can effectively segment the defect in resin continuous phase, therefore the infiltration rate of aggressive medium is effectively restrained. After system cured, the high crosslinked net structure and flake structure can effectively resistant the corrosion damage. Furthermore, the stainless steel flakes epoxy intermediate nano-coating has tenacity film, excellent matching with primer and finish coating, good adhesion and good water, oil, alkali, salt mist and dilute hydrochloric acid resistance.

Formerly study and application indicated that the heavy-duty organic coating had excellent corrosion resistance and protection for matrix [1]. But in the engineering practice, we found that the coating drying time was too long, leading to the construction period too long. Formerly practical construction experience stated that adding curing agent could short the drying time in confirm humidity and temperature of construction experiment. However, the solidification principle of organic coating is that the curing agent crossing linking reacts with resin producing structure stable cross-linked product [2-4]. Therefore the curing agent content will affect the coating curing molding process, and may influence the property of coating. In this study, on the basis of standard curing agent content, through adding curing agent content, we researched the influence of curing agent content on the viscosity, applied time, hardness, combining power, drying time and corrosion resistance of the stainless steel flakes epoxy intermediate nano-coating. To provide reference and according for further coating optimization, shorting process cycle and raising project benefit.

\section{Experimental Methods}

The stainless steel flakes epoxy intermediate nano-coating was produced by Zhongke Engineering Research Center for Corrosion Control, Shenyang (Institute of Metal Research, Chinese Academy of Sciences). There were two different size samples and the matrix is low-carbon steel. The size of bigger for property measurements was $100 \mathrm{~mm} \times 60 \mathrm{~mm} \times 6 \mathrm{~mm}$ and the size of smaller samples for electrochemical measurements was $100 \mathrm{~mm} \times 60 \mathrm{~mm} \times 6 \mathrm{~mm}$. The stainless steel flakes epoxy intermediate nano-coating was processed with the thickness of $120 \mathrm{um}$, the curing agent content of standard, standard 1.5, 2, 2.5, 3 times and the coating process of manual brushing. 
To evaluate the effect of curing agent content on the property of the stainless steel flakes epoxy intermediate nano-coating, the viscosity of the coating was measured by Tu-4(GB/T 1723-93), the combining power of coating with matrix was measured by HATE hydraulic pressure combining power tester, and the hardness of coating was measured by HVS-1000Z automatic turntable digital micro rigidity with load of $0.098 \mathrm{~N}$. In order to evaluate the effect of curing agent content on the corrosion resistance of the stainless steel flakes epoxy intermediate nano-coating, the small sample was used in electrochemical tests, and the copper wire was welded to the edge of the test piece. Except the unilateral exposed corrosion surface of $10 \mathrm{~mm} \times 10 \mathrm{~mm}$, the other surfaces were all coated with 704 silicon rubber. The Electrochemical Impedance Spectroscopy (EIS) was conducted on electrochemical workstation of PARSTAT2273 by using a three-electrode electrolysis cell with a saturated calomel electrode as reference electrode and platinum as counting electrode. The electrolyte was same as the solution used in the salt fog test. The sine wave with amplitude of $5 \mathrm{mV}$ vs. open circuit potential and the frequency of $10 \mathrm{mHz} \sim 100 \mathrm{kHz}$ were adopted in the Electrochemical Impedance Spectroscopy test.

Table 1. Heavy-duty organic coating

\begin{tabular}{|c|c|}
\hline Composition & Thickness $(\mu \mathrm{m})$ \\
\hline Zinc rich epoxy primer nano-coating & 80 \\
\hline Sealing epoxy primer nano-coating & 60 \\
\hline Stainless steel flakes epoxy intermediate nano-coating & 120 \\
\hline Sealing epoxy finish nano-coating & 120 \\
\hline Total thickness & 380 \\
\hline
\end{tabular}

\section{Results and Discussion}

Figure 1 shows the viscosity changing trend of the coating with different curing agent content in different time. Initially, the viscosity of the coating reduces with the content of curing agent increased. But with the time extending, the viscosity of the coating gradually increases. The coating with standard curing agent content has the highest final viscosity and the 2 times of standard curing agent content coating has the lowest final viscosity. We consider that the curing agent dispersing in the resin increases the activity of resin chains when the curing agent is adding in the coating initially. Therefore, the higher the curing agent content, the resin more dispersed, so the viscosity of the coating reduces. With the time extending, the curing agent crossing linking reacts with resin producing cross-linked product. The longer the time, the more cross-linked product produced, so the viscosity of the coating raises.

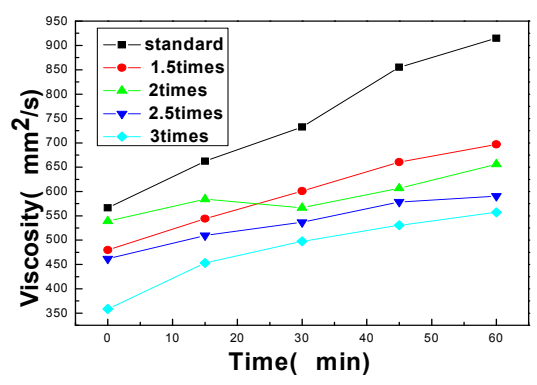

Figure 1. Viscosity changing trend of the coating with different curing agent content in different time

The coating is identified as unapplied when the coating is gelatineous mixed, could not free fall provoked with stick and the state could not improve after adding thinner. The drying time of the 
coating can be classified to surface dry, practical dry and completely dry according to GB/T1728-1979. In the text, we use finger touch method to determine coating surface and practical dry [5]. The completely dry is judged by wiping the sample surface with gauze dipping with thinner. When the gauze could not taint with coating, the coating is totally curing meaning the coating completely dry. The drying time of coating is measured in the environment with daytime temperature of $16.6 \sim 18.3^{\circ} \mathrm{C}$ and humidity of $35 \sim 40 \%$, and night time temperature of $10.5 \sim$ $12.0^{\circ} \mathrm{C}$ and humidity of $45 \sim 50 \%$. The measured time is shown in Table 2.

The text results indicates that with the curing agent content increasing, the surface drying time of coating don't change, the practical and completely drying time obviously short. The practical drying time can be mostly short $15 \mathrm{~h}$, and completely drying time at least $24 \mathrm{~h}$. But adding curing agent content obviously short the coating applying time, the coating after mixed must be used up in $6 \mathrm{~h}$ when the curing agent content is 3 times of standard.

Table 2. The coating drying time with different curing agent content $(\mathrm{h})$

\begin{tabular}{|c|c|c|c|c|}
\hline $\begin{array}{c}\text { Curing agent } \\
\text { content }\end{array}$ & $\begin{array}{c}\text { Surface drying } \\
\text { time }(\mathrm{h})\end{array}$ & $\begin{array}{c}\text { Practical drying } \\
\text { time }(\mathrm{h})\end{array}$ & $\begin{array}{c}\text { Completely } \\
\text { drying time }(\mathrm{h})\end{array}$ & $\begin{array}{c}\text { Applying } \\
\text { time }(\mathrm{h})\end{array}$ \\
\hline Standard & 9 & 48 & 60 & 12 \\
\hline 1.5 times & 9 & 48 & 60 & 12 \\
\hline 2.0 times & 9 & 36 & 48 & 9 \\
\hline 2.5 times & 9 & 36 & 48 & 9 \\
\hline 3.0 times & 9 & 33 & 36 & 6 \\
\hline
\end{tabular}

The combining power and hardness of the coating with different curing agent content is shown in Table 3. The combining power and hardness of the coating both increase firstly and then decrease as the curing agent content adding. We consider that the crossing linking reaction of resin is more fully, as the curing agent content adding, so the combining power of the coating increasing. And the crossing linked resin raise, the flexible chain decrease, and then the hardness of the coating increase. However, when more curing agent added, the active group of curing agent is more than resin, excess curing agent could not take part in the crossing linking reaction and disperse in the macromolecules, causing the combining power of the coating declined [6]. And the excess curing agent decrease the cross-linking density of resin, decrease the content of rigid group in curing resin, leading to the hardness of the coating decrease as more curing agent adding.

Table 3. The coating combining power and hardness with different curing agent content

\begin{tabular}{|c|c|c|c|c|c|}
\hline Curing agent content & Standard & 1.5 times & 2 times & 2.5 times & 3 times \\
\hline Combining power (MPa) & 8.2 & 8.4 & 9.5 & 7.6 & 7.5 \\
\hline Hardness (HV0.01) & 10.9 & 11.2 & 14.5 & 13.1 & 12.4 \\
\hline
\end{tabular}

The prepared electrochemistry samples with different curing agent content were immersed in solution of $3.5 \% \mathrm{NaCl}$. After immersed $0 \mathrm{~d}, 7 \mathrm{~d}, 15 \mathrm{~d}$ and $30 \mathrm{~d}$, the EIS of the coating have been measured. The measurement result is shown in Fig.2. We can see that all the impedance of coating with different curing agent content decline as the immersing time prolong. But all of the impedance of coating with different curing agent content is nearly the same as the coating with standard curing agent content in all immersing time. Which indicate the corrosion resistance of the coating not influenced by the curing agent content adding. 


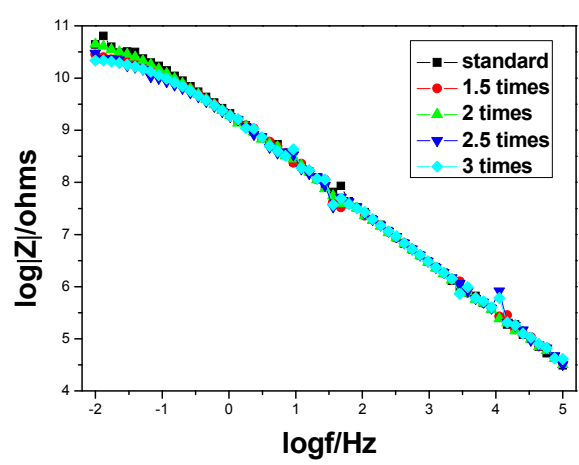

a) $0 \mathrm{~d}$

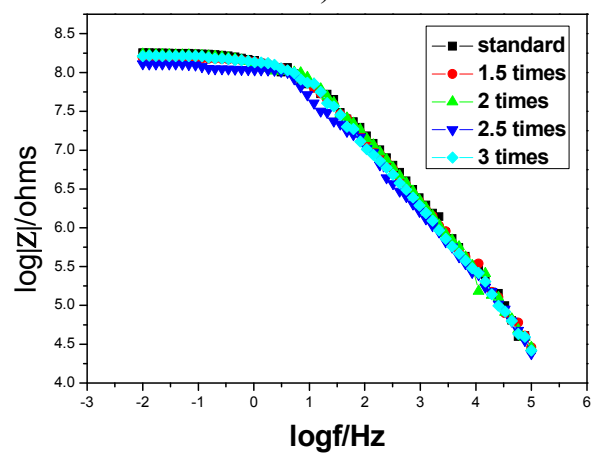

c) $15 \mathrm{~d}$

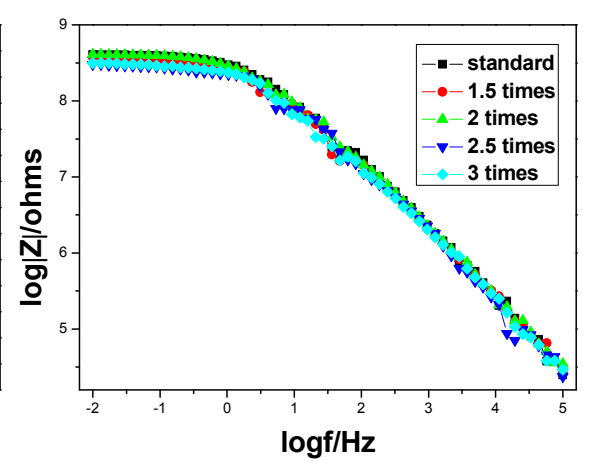

b) $7 \mathrm{~d}$

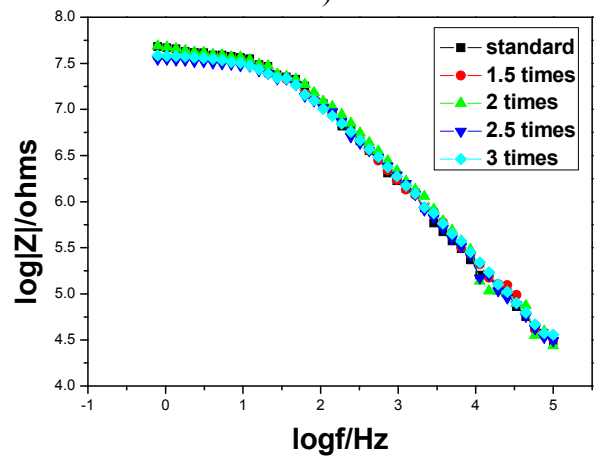

d) $30 \mathrm{~d}$

Figure 2. Bode plots of the coating with different curing agent content in different immersed time

\section{Conclusions}

The curing agent content obviously influence the viscosity, applied time, hardness, combining power, drying time of the stainless steel flakes epoxy intermediate nano-coating. As the curing agent content adding, the viscosity decrease, applied time short, drying time short, combining power and hardness both increase firstly and then decrease. It is considered that on the one hand, adding curing agent content make the crossing linking reaction of resin more fully and faster. But on the other hand, when more curing agent added, the active group of curing agent is more than resin, excess curing agent could not take part in the crossing linking reaction and disperse in the macromolecules, excess curing agent decrease the cross-linking density of resin, decrease the content of rigid group in curing resin. The EIS measurement results indicate, in experiment time, the changing of microscopic group will not influence the corrosion resistance of the coating.

\section{References}

[1] Zhou Meng, Ma Chunlin, The corrosion resistance of nano organic coatings on $16 \mathrm{MnR}$ steel, Corrosion and Protection. 32 (2011) 704-707.

[2] Chai Hongmei, Wang Peng, The effect of curing agent on the curing properties of epoxy resin system for RTM, Glass Fiber Reinforced Plastics/ Composites. 6 (2009) 48-49.

[3] K.M. Arthur, M.I. Hugh, Expoxy resin curing agent, U.S. 3898251 A[P], 1975.

[4] Wan Jintao, The study of preparation and properties of epoxy resin curing dendrimers, Doctoral Dissertation of Zhejiang University, 2010, pp.6-7.

[5] Pan Jimin, Practical handbook of coatings, Machinery Industry, 2014, pp. 129.

[6] Li Qingwei, Study of preparation and corrosion resistance of polyaniline/ epoxy composite coatings, Master Thesis of Jilin University, 2016, pp. 28-30. 